\author{
Cadernos de \\ ESTUDOS LINGḯlíTICOS - (55.1), Campinas, Jan./Jun. 2013
}

\title{
ELEMENTOS NUCLEARES DE FRAME E A INTERPRETAÇÃO DE METÁFORAS
}

\author{
HERONIDES MOURA ${ }^{1}$
}

\begin{abstract}
RESUMO
Neste artigo, examina-se como os frames associados aos veículos de enunciados metafóricos interferem na interpretação desses enunciados. Os dados analisados consistem de metáforas com os verbos mergulhar, afogar-se e imergir. Conclui-se que os Elementos Nucleares de Frame são preservados nos enunciados metafóricos. Além disso, tanto o esquema imagético de contêiner, quanto o conteúdo conceitual provido pelos argumentos dos verbos são também relevantes para a interpretação das metáforas.
\end{abstract}

Palavras-chave: frame; metáfora; esquema de imagem.

\begin{abstract}
In this article, it is investigated which are the effects of frames evoked by vehicles of metaphors, upon interpretations of these metaphors. The data studied consists of metaphors with the Portuguese verbs mergulhar (to plunge), afogar-se (to drown) e imergir (to immerse). It is concluded that core frame elements are preserved in the metaphoric assertions. Moreover, both the container imageschema and the conceptual content provided by arguments of the verb are also important for metaphor interpretation.

Keywords: frame; metaphor; image-schema.
\end{abstract}

\section{INTRODUÇÃO}

Neste artigo, vou analisar metáforas com os verbos mergulhar, afogar-se e imergir, com base nos respectivos frames desses itens lexicais, tais como descritos no projeto FrameNet. Mostrarei que as interpretações das metáforas estudadas são construídas com base em três elementos: os frames associados aos itens lexicais, o esquema imagético de contêiner e os conceitos associados aos argumentos dos verbos em questão.

Os verbos estudados se ligam a três frames: MOVIMENTO_DIRECIONAL, MORTE e COLOCAR. Esses frames definem os Elementos de Frame, que são muito importantes para a interpretação de metáforas com os verbos em questão. Por outro lado, há traços importantes nas sentenças metafóricas estudadas, que não são captados pelos elementos dos frames. Argumentarei que esses traços semânticos

1. UFSC/CNPq, Florianópolis, Brasil. heronides@uol.com.br 
MOURA - Elementos nucleares de frame e a interpretação ...

provêm tanto do esquema imagético de contêiner, quanto dos conceitos associados aos argumentos dos verbos.

Frames e esquemas imagéticos impõem padrões interpretativos para as metáforas. No entanto, essa tendência à padronização é contraposta pela combinação específica de argumentos e verbos, gerando uma interação entre significados que não é inteiramente previsível com base apenas nos frames e no esquema imagético.

Assim, a hipótese deste artigo é que frames e esquemas cognitivos são complementados com a concretude de conceitos específicos, gerando interpretações que não são inteiramente redutíveis aos frames e aos esquemas cognitivos.

$\mathrm{O}$ artigo está estruturado em sete seções. Na seção 1 a seguir, apresento as definições e os Elementos Nucleares dos Frames MOVIMENTO_DIRECIONAL, MORTE e COLOCAR, e procedo à identificação desses elementos de frame em sentenças metafóricas com os verbos mergulhar, afogar-se e imergir, respectivamente.

Na seção 2, investigo as diferenças de frames no português e no inglês. Argumento que a polissemia dos verbos estudados, em português, não encontra uma contrapartida perfeita na língua inglesa, o que faz com que haja diferença entre os frames associados às unidades lexicais, nas duas línguas.

Na seção 3, são discutidas as regras e elementos constituintes do esquema imagético de contêiner, que está associado aos verbos objeto deste estudo (mergulhar, afogar-se e imergir). São definidos os seguintes elementos do esquema imagético de contêiner: Tridimensionalidade, Oposição dentro/fora, Limites, Completude da ação e Afetação do Tema. Em seguida, finalizando a seção 3, procedo à identificação desses elementos em metáforas com os verbos estudados.

Na seção 4, argumento que os elementos de frame e os elementos de esquema imagético, embora essenciais para a interpretação das metáforas estudadas, não esgotam o significado das sentenças não literais. A hipótese adotada é que a combinação de dois conceitos em um contexto específico é o que define a especificidade da interpretação de cada sentença metafórica. Finalmente, na seção 5, são feitas as considerações finais, e depois, na seção 6, é apresentada a lista de referências.

\section{OS FRAMES MOVIMENTO_DIRECIONAL, MORTE E COLOCAR.}

Nesta seção, vou examinar os frames associados aos itens lexicais mergulhar, se afogar e imergir, e identificar como os Elementos Nucleares de cada um desses frames se apresentam em metáforas que fazem uso desses itens lexicais.

Em primeiro lugar, será examinado o verbo mergulhar. Uma tradução possível, em inglês, do verbo mergulhar é o verbo to plunge. Este verbo está 
associado, no FrameNet para a língua inglesa ${ }^{2}$, aos frames MOVIMENTO DIRECIONAL e COLOCAR.

A definição do frame MOVIMENTO_DIRECIONAL é a seguinte: "Neste frame, o TEMA se move em uma certa Direção, que é frequentemente determinada pela gravidade ou outras forças naturais e físicas"’.

O frame MOVIMENTO_DIRECIONAL apresenta seis Elementos Nucleares de Frame: Área, Direção, Meta, Trajeto, Fonte e Tema. Os Elementos de Frame substituem e ampliam o conceito de papel temático: "Os Elementos do Frame, na versão mais recente da teoria, são de fato Funções Microtemáticas, postuladas em relação ao frame a que se referem" (SALOMÃO, 2009, p.173).

Podemos identificar, na metáfora em (1) abaixo, com o verbo mergulhar, em português, cinco Elementos de Frame, ainda que não estejam sintaticamente representados na sentença. O único Elemento Nuclear de Frame que a sentença abaixo não apresenta é a área, pois o movimento metaforizado é linear, ocorrendo na linha do tempo, que corresponde ao trajeto.

(1) Espanha volta a mergulhar na recessão econômica. www.folhape.com.br/ cms/opencms/folhape/pt/.../07.../0006.html

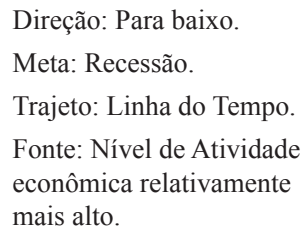

Quadro 1: Elementos do Frame MOVIMENTO_DIRECIONAL, associado à metáfora com o verbo mergulhar

Será descrito agora o frame associado ao verbo se afogar. A tradução de se afogar, em inglês, é o verbo to drown. Este verbo está associado ao frame MORTE, no FrameNet. O frame MORTE recebe a seguinte definição: "As palavras neste frame descrevem a morte de um Protagonista. A Causa da morte também pode ser expressa de forma indireta"4. (https://framenet2.icsi.berkeley.edu).

O Elemento Nuclear do Frame MORTE na metáfora em (2) abaixo, com o verbo se afogar, é o Protagonista, que, no caso, são vários: artistas, atletas e todo tipo de gente de vida pública:

(2) E Bedurri seguiu listando histórias de pessoas famosas, entre elas artistas, atletas e todo tipo de gente de vida pública que se afogou na depressão,

2. Existe um projeto FrameNet em português (http://www.framenetbr.ufjf.br/), mas ele ainda se encontra em fase de desenvolvimento e não apresenta os verbos mergulhar, afogar-se e imergir.

3. A tradução é minha. Foi mantida no original a marcação de cores dos elementos de frame.

4. Tradução minha. Mantive no original a marcação em cores dos elementos de frame. 
MOURA - Elementos nucleares de frame e a interpretação ...

no álcool e em outras drogas. http://www.seculodiario.com/arquivo/2003/ dezembro/06_07/colunistas/tavares/index.asp

Além desse Elemento Nuclear de Frame, é importante destacar outro Elemento de Frame, desta vez não nuclear, que vem a ser a Causa da morte, que recebe expressão sintática na sentença (2) acima: depressão, álcool e outras drogas. Estas são as Causas da morte (metafórica ou real) do(s) Protagonista(s).

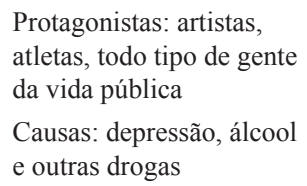

Quadro 2: Elementos do frame MORTE, associado à metáfora com o verbo se afogar

Finalmente, passo à análise do frame associado ao verbo imergir. Em inglês, este verbo pode ser traduzido por to immerse. No FrameNet, to immerse é associado ao frame COLOCAR (Placing). O frame COLOCAR apresenta quatro Elementos Nucleares de Frame: Agente, Causa, Meta e Tema. O verbo imergir pode ser usado em metáforas como (3), abaixo:

(3) Elaborar esse plano nos fez imergir na cultura dessa região. planetadisney.com.br/tag/marcos-rosset/

Nesta metáfora, podemos identificar três Elementos Nucleares do Frame COLOCAR, como se pode ver no Quadro 3, abaixo:

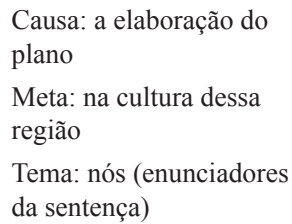

Quadro 3: Elementos do Frame COLOCAR, associado à metáfora com o verbo imergir

As sentenças metafóricas de (1) a (3) ilustram como as interpretações figurativas são calcadas nos frames associados aos verbos que são os veículos das metáforas. Há, assim, uma continuidade entre padrões gramaticais e semânticos dos usos literais e os padrões gramaticais e semânticos de usos não literais (MOURA, 2006 e 2007; MOURA \& ZANOTTO, 2009; VEALE, 2003). Os usos não literais herdam parte das estruturas dos usos literais. 


\section{DIFERENÇAS DE FRAMES ENTRE O PORTUGUÊS E O INGLÊS.}

Antes de continuar a análise dos outros fatores relevantes para a interpretação das metáforas estudadas neste artigo, é importante observar que os itens lexicais de uma dada língua, quando traduzidos, não necessariamente estão associados aos mesmos frames em línguas diferentes (ALTERNBERG \& GRANGER, 2002; LÖNNEKER-RODMAN, 2007).

Assim, por exemplo, se um item lexical $L$ está associado a um frame $F 1$ na língua da qual faz parte, a tradução de $L$ não necessariamente está associada a este frame $F 1$, ou não está associada a apenas a este frame $F 1$.

Consideremos, agora, um exemplo em que o verbo mergulhar é usado num contexto muito similar ao do verbo imergir, tal como exemplificado na sentença (3) Elaborar esse plano nos fez imergir na cultura dessa região. Assim como imergir, o verbo mergulhar está associado ao frame COLOCAR, na sentença (4) abaixo:

(4) Com uma linguagem simples e envolvente Fernando Dolabela nos faz mergulhar na cultura empreendedora.

dimensaohumana.blogspot.com/2007/.../insight-o-segredo-de-lusa.ht...

A vinculação a um ou outro frame é essencial para a interpretação da metáfora. Por exemplo, no caso da sentença (1) Espanha volta a mergulhar na recessão econômica, os Elementos Nucleares do Frame MOVIMENTO_DIRECIONAL (ou seja, Direção, Trajeto e Fonte) são constituintes essenciais da interpretação da metáfora. Já na sentença (4) acima, esses Elementos de Frame não estão presentes. O que importa, em (4), é o efeito que a ação tem sobre o Tema, quando este chega à Meta. Quer dizer, o que importa é o efeito do mergulho dos leitores (Tema), na cultura empreendedora (Meta). A polissemia do verbo mergulhar, em português, não coincide com o significado do verbo to immerse em inglês, e isso faz com que os frames com os quais o verbo mergulhar se associa sejam diferentes dos frames com os quais o verbo to immerse se associa.

Além dessa diferença importante na polissemia dos verbos nas diferentes línguas, há também diferenças entre os próprios frames. Por exemplo, foi visto que o verbo se afogar pode ser traduzido por drown, e que este verbo está associado ao frame MORTE. O problema é que o verbo se afogar não necessariamente implica morte, em português:

(5) A amiga me cutuca e fala: "MENINAA, olha que menino gato", ai eu fiquei olhando,quando ele passou na minha frente,eu tomei aquele caldo e me afoguei. www.youtube.com/user/MsJapinha123

O verbo se afogar, em (5), indica uma ação que provoca um dano físico (sufocação, engolir água), e que poderia levar à morte, mas não necessariamente. 
MOURA - Elementos nucleares de frame e a interpretação ...

Em português, o verbo se afogar é ambíguo entre dois sentidos: a) morte por sufocação e b) sufocação por estar submerso na água. Essa distinção entre dano físico que não leva à morte e dano que conduz à morte se encontra em várias unidades lexicais do português, tais como se enforcar, atropelar, linchar, esganar e sufocar.

Como representar essa ambiguidade de verbos como linchar e se afogar, em termos de frames? Uma possibilidade seria criar um frame que envolvesse dano físico grave, mas sem ocorrência de morte. A FrameNet já dispõe de um frame para indicar Dano (Damaging), o qual abrange unidades lexicais como damage (danificar), vandalize (vandalizar), scrape (raspar), sabotage (sabotar), etc. Essa lista, no entanto, não abrange verbos como se afogar, se enforcar, atropelar, linchar, esganar e sufocar.

O verbo suffocate (sufocar), por exemplo, é uma unidade lexical associada ao frame MORTE e não ao frame Dano, mas, em português, o verbo sufocar é polissêmico entre dano que não leva à morte, e ação que causa a morte. Em suma, a representação da polissemia de verbos como se afogar pode levar a alterações nos frames que são válidos para a língua inglesa, mas não necessariamente para o português.

Essa polissemia da unidade lexical se afogar é também importante para a interpretação de metáforas envolvendo esse verbo. O afogamento, nas metáforas, pode ser visto como letal ou não.

$\mathrm{Na}$ sentença (6) abaixo, o afogamento nas drogas é percebido como a causa que levou à morte de Amy Winehouse. Nesse caso, o verbo se afogar está vinculado ao frame MORTE:

(6) (Amy Winehouse) Tão linda, tão jovem, uma voz inigualável, uma vida inteira pela frente, um talento único, e ainda se afogou nas drogas e bebidas. rehab-rehab-rehab.tumblr.com/post/8025453934

Já na sentença (7), o afogamento nas drogas não implica morte:

(7) Ele se afogou nas drogas, na cachaça e foi até preso dia desses. www.orkut.com > ... > JÁ NAMOREI UM MONSTRO !!! > Fórum:

Pode-se concluir, portanto, que as diferenças de significado de um item polissêmico são relevantes para a interpretação das metáforas, e que essas diferenças devem ser levadas em conta na representação dos frames que estão associados às unidades lexicais.

\section{O ESQUEMA IMAGÉTICO DE CONTÊINER}

Um segundo fator importante para a compreensão das metáforas analisadas é o esquema imagético associado aos verbos se afogar, mergulhar e imergir. Esse esquema imagético é o de contêiner (JONHSON, 1987; LAKOFF, 1987). 
Esse esquema imagético define alguns elementos topológicos, tais como limite (boundary), dentro e fora.

Relações espaciais topológicas são aquelas que permanecem constantes quando submetidas a transformações e deformações (LEVINSON, 2003, p. 71). Relações topológicas não são sensíveis a formas e angulação (PIAGET, J \& INHELDER, 1967). Por exemplo, a preposição em estabelece uma relação topológica na sentença $O$ quadro está encostado na parede, pois a angulação do quadro em relação à parede não afeta a relação espacial estabelecida (cf. TALMY, 2003; MOURA \& DAMÁZIO, 2011). Igualmente, numa sentença como A menina colocou o suco de uva no copo, a relação topológica (o suco passou para dentro do copo) não depende da forma específica do copo. O esquema imagético de contêiner impõe uma lógica básica, com as seguintes regras (LAKOFF, 1987): $i$. Todo objeto está dentro ou fora de um contêiner, o que equivale à regra do terceiro excluído: $P$ ou não $P$; ii. Se um contêiner $A$ está dentro de um contêiner $B$ e o objeto $X$ está dentro de $A$, então $X$ está em $B$.

Além dessas duas regras de natureza lógica, o esquema imagético de contêiner define também que os limites impedem que entidades externas entrem em contato com o que está dentro da região delimitada pelo contêiner. Além disso, se uma entidade externa entra no contêiner, ela é afetada pelo que está dentro do contêiner (JONHSON, 1987; PEÑA, 2001).

Comparando-se o frame COLOCAR com o esquema imagético de contêiner, pode-se observar que a Meta, que é um elemento nuclear do frame COLOCAR, não precisa ser um contêiner. A Meta pode ser tanto uma superfície, quanto um contêiner.

Em suma, o frame COLOCAR define um padrão gramatical e semântico mais amplo que o esquema imagético de contêiner. $O$ esquema imagético de contêiner especifica que os limites são tridimensionais. Essa tridimensionalidade deriva da corporeidade do esquema imagético: nossos corpos são tridimensionais e não superfícies planas bidimensionais.

Assim, os verbos se afogar, mergulhar e imergir estão vinculados ao esquema imagético de contêiner, o que implica que o Elemento de Frame Meta deve ser interpretado como um objeto tridimensional. As sentenças abaixo exemplificam essa tridimensionalidade:

(8) Bombeiros encontram corpo de turista que se afogou no Lago de Furnas. www.viaeptv.com.

(9) Depois o brother mergulhou na piscina, como sempre fez ao voltar de um paredão. ofuxico.terra.com.br

(10) De acordo com Vitrúvio, Arquimedes pediu a Hierão uma porção de ouro que pesasse o mesmo que a coroa. Imergiu-a em seguida em um recipiente cheio de água até a borda. books.google.com.br/books?isbn=8571104751.

Lago de Furnas, piscina e recipiente são objetos tridimensionais. É interessante observar que essa tridimensionalidade deriva, muitas vezes, do próprio esquema imagético associado ao verbo, e não do conteúdo semântico 
MOURA - Elementos nucleares de frame e a interpretação ...

dos substantivos. Por exemplo, o substantivo lago pode ser interpretado como bidimensional, se o foco recai sobre a superfície do lago. Pinker (2008, p. 211) observa que a dimensionalidade de um objeto depende da forma como pensamos nele. Tendemos a pensar num lago como sendo bidimensional, mas o uso do verbo se afogar, na sentença (8), muda a nossa perspectiva e passamos a ver o lago como tridimensional, pois uma pessoa só pode se afogar num volume de água, e não numa superfície.

No caso do substantivo lago, portanto, a tridimensionalidade deriva do esquema imagético de contêiner associado ao verbo se afogar. No caso de outros substantivos, como recipiente, a tridimensionalidade deriva diretamente do frame CONTÊINERES (Containers), ao qual estes substantivos estão associados. O caráter tridimensional do contêiner também explica uma das regras do esquema imagético que estamos analisando. Essa regra, já citada mais atrás, é a seguinte: limites impedem que entidades externas entrem em contato com o que está dentro da região delimitada pelo contêiner. Um recipiente tem limites que impedem a entrada do que está fora. Já uma superfície bidimensional não parece estabelecer um obstáculo, embora uma superfície tenha uma delimitação. Pensemos no seguinte exemplo: uma formiga pode circular livremente pelo chão de uma sala, mas ela terá de escalar as bordas de um copo, se quiser beber o que há dentro dele. O chão não impõe um limite; o copo, sim.

Além disso, os verbos que selecionei para análise impõem, é claro, que o contêiner contenha um líquido. Finalmente, um aspecto importante da semântica dos verbos se afogar, mergulhar e imergir é que todos eles transmitem uma ideia de completude da ação. A imersão no volume líquido deve ser completa. Essa completude da ação provavelmente deriva do próprio esquema imagético de contêiner, em especial da regra Todo objeto está dentro ou fora de um contêiner. Assim, a imersão de um objeto num líquido é pensada como completa. Reveja a sentença (8): Bombeiros encontram corpo de turista que se afogou no Lago de Furnas. Não faz sentido imaginar um afogamento sem imersão total do corpo no lago.

A oposição entre dentro/fora, em relação a um contêiner, pode ser, de fato, uma questão de gradação. Parte do objeto pode estar mais para dentro, ou mais para fora. Segundo Langacker (2002), a língua asteca cora apresenta uma gama muito rica de usos para os conceitos espaciais de dentro/fora, representados, respectivamente, pelos morfemas $u$ e $a$. Num dos usos desses conceitos, criase uma oposição entre "inserção profunda no interior" e "inserção superficial no interior", a primeira marcada pelo morfema $u$, e a segunda pelo morfema $a$. Ou seja, $u$ passa a significar algo como "inteiramente dentro", por oposição ao morfema $a$, que passa a significar "parcialmente dentro". Como afirma Langacker (2002, p. 40), "como $u$ e $a$ funcionam, de um modo bastante consistente, como um par contrastivo, o esperado é que a oposição dentro/fora possa ser, em alguns casos, mais relativa que absoluta". 5

\footnotetext{
5. Tradução minha.
} 
Assim, na língua cora, a ação de colocar o chapéu na cabeça de alguém é indicada com o morfema $u$, pois a cabeça entra completamente no chapéu, ao passo que a ação de escavar um tronco, para fazer uma canoa, é marcada com o morfema $a$, indicando que o ato de escavar atingiu parte do tronco, e não o tronco inteiro.

No caso dos verbos se afogar, mergulhar e imergir, a imersão é total, de modo que a semântica desses verbos implica a completude da ação. Esse traço semântico, associado ao esquema imagético de contêiner, afeta diretamente a interpretação metafórica que se faz desses itens lexicais.

(11) Você mergulhou no trabalho com tudo, e acha que é só por isso que não tem tempo para sua família. www.ejesus.com.br

Nesse uso metafórico do verbo mergulhar, a completude da ação é essencial para a compreensão da metáfora. Completude também está ligada, nos usos metafóricos, à intensidade da ação. Essa extensão metafórica do verbo mergulhar está registrada na acepção 8 (oito) do verbete mergulhar, no Dicionário Houaiss da Língua Portuguesa. A referida acepção é definida da seguinte forma: "entregarse inteiramente a (uma ocupação, uma atividade)" (HOUAISS, 2001, p. 1899). $\mathrm{O}$ advérbio inteiramente, usado na definição, marca tanto a completude da ação, quanto a sua intensidade.

Outro elemento semântico importante do esquema imagético de contêiner é a seguinte condição, já citada mais acima: se uma entidade externa entra no contêiner, ela é afetada pelo que está dentro do contêiner. Essa regra implica que a representação cognitiva de mudança de lugar (colocar $x$ em um contêiner $y$ ) está ligada a uma representação cognitiva de mudança de estado ( $x$ é afetado pelo que está em $y$ ).

Essa relação entre mudança de lugar e mudança de estado extrapola o esquema imagético de contêiner, envolvendo qualquer tipo de ação de colocar um objeto em um determinado lugar, seja este lugar tridimensional ou não.

Pinker (2008) observa que a flexibilidade da mente humana, com sua capacidade de modificar enquadramentos e fazer alterações gestálticas, permite enquadrar uma mesma cena como envolvendo tanto mudança de lugar, quanto mudança de estado. Depende do foco que se dá à cena. "Quando bato na parede com um bastão, estou afetando o bastão por movê-lo até a parede ou afetando a parede e usando o bastão como instrumento?" (PINKER, 2008, p. 69). Pinker (2008) ressalta que a mudança de estado ocorre tanto com o Tema, quanto com a Meta do movimento. Assim, no exemplo dele, o bastão, que é o Tema, pode funcionar como a entidade afetada, pois o bastão se deslocou no espaço. Por outro lado, a parede, que é a Meta, pode ser percebida como o elemento afetado. A afetação da Meta licencia a alternância de locativo, como se pode ver no exemplo abaixo:

$\left(12^{\mathrm{a}}\right)$ Ele esfregou graxa no eixo.

$\left(12^{\text {b }) ~ E l e ~ e s f r e g o u ~ o ~ e i x o ~ c o m ~ g r a x a . ~(e x e m p l o s ~ r e t i r a d o s ~ d e ~ P i n k e r, ~ 2008, ~ p .71) . ~}\right.$ 
MOURA - Elementos nucleares de frame e a interpretação ...

Na sentença $\left(12^{\mathrm{a}}\right)$, o Tema graxa é o foco da cena, e ocupa a posição de objeto direto, ao passo que o eixo, que é a Meta, ocupa uma posição sintática mais periférica, de adjunto. Nesse caso, o que importa é o que acontece com o Tema, que se moveu de lugar e foi afetado por esse movimento. Já na sentença $\left(12^{b}\right)$, a Meta eixo é o foco da cena, e ocupa a posição de objeto direto, ao passo que o Tema graxa é rebaixado para uma posição sintática mais periférica, de adjunto. Nessa sentença, o mais importante é o estado da Meta depois da ação.

A regra se uma entidade externa entra no contêiner, ela é afetada pelo que está dentro do contêiner enfatiza a afetação do Tema, e não da Meta (o recipiente). Mas na verdade se trata de uma via de mão dupla: tanto o Tema, quanto a Meta podem ser afetados pela mudança de lugar. Por exemplo, se se coloca cloro numa piscina, o cloro se dissolve, e a piscina muda de cor. Cloro (tema) e piscina (Meta) são ambos afetados pela ação.

No FrameNet, os frames COLOCAR e ENCHER (Filling) se distinguem pela ênfase na afetação do Tema, no caso de COLOCAR, e na afetação da Meta, no caso de ENCHER.

Verbos como fill (encher), smear (esfregar), plaster (emplastar), dab (esfregar, passar a esponja) e coat (cobrir com camada, revestir), entre outros, são unidades lexicais associadas ao frame ENCHER. Na língua inglesa, verbos como smear, plaster, dab e coat aceitam a alternância de locativo, observada nos exemplos $12^{\mathrm{a}}$ e $12^{\mathrm{b}}$ (cf. PINKER, 2008). Essa alternância sintática corresponde à observação, contida na definição do frame ENCHER, de que "a área ou contêiner podem aparecer como objeto direto em todos estes verbos (https://framenet2.icsi. berkeley.edu/fnReports/data/frameIndex.xml?frame=Filling). O status de afetado atribuído à Meta licencia a posição sintática mais proeminente de objeto direto. No entanto, o verbo to fill (encher) não permite a alternância, pois a Meta, neste tipo de verbo, só pode aparecer na posição de objeto direto, e não na de adjunto. Essa restrição vale tanto para o inglês, quanto para o português:

(13) He could fill a flask with coffee. (Ele podia encher um cantil com café) (14) * He could fill coffee into a flask. (*Ele podia encher café num cantil).

Assim, os verbos ligados ao frame ENCHER se distribuem em duas classes sintáticas diferentes: os que permitem as duas formas da alternância de locativo, como o verbo to smear (esfregar) e os que não permitem essa alternância, como o verbo to fill (encher). Há, no FrameNet, a observação de que, nos verbos ligados ao frame ENCHER, a Meta pode ser promovida à posição de objeto direto. É importante acrescentar que, em alguns verbos, essa promoção sintática é obrigatória, como to fill (encher), e opcional em outros verbos, como to smear (esfregar).

Quanto à perspectiva de afetação do Tema ou da Meta, os verbos estudados aqui (se afogar, mergulhar e imergir) se situam no frame COLOCAR, ou seja, a perspectiva é de afetação do Tema, quando em contato com a Meta. A alteração da Meta, embora possível, é secundária. Assim, afetação da Meta é um elemento semântico associado aos verbos em questão, tanto em função do 
Cadernos de ESTUDOS LINGḯsTIICOS (55.1) - Jan./Jun. 2013

frame COLOCAR, quanto em função do esquema imagético de contêiner. No que concerne à perspectiva de afetação do Tema, o frame COLOCAR se opõe ao frame ENCHER.

Como resumo do que acabou de ser discutido, o Quadro 4 abaixo identifica os elementos semânticos dos verbos se afogar, mergulhar e imergir, que derivam do esquema imagético de contêiner.

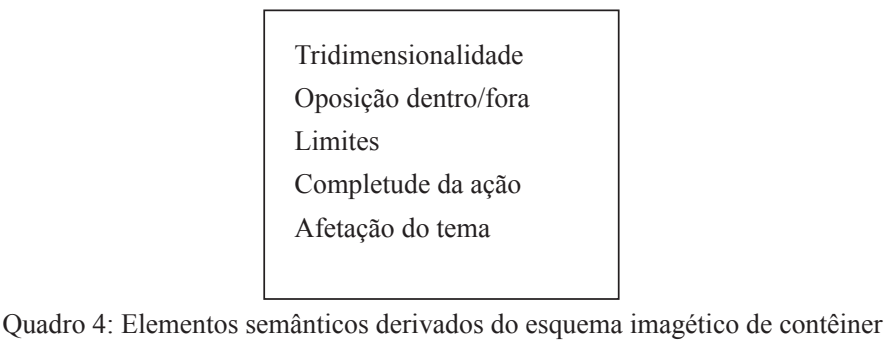

Passo, agora, ao exame de como esses elementos semânticos afetam a interpretação de metáforas com os verbos estudados. Analisemos, mais uma vez, a sentença (1) Espanha volta a mergulhar na recessão econômica. Vou identificar como cada um dos elementos do Quadro 4 afeta a interpretação dessa sentença. Em primeiro lugar, pode-se observar que a tridimensionalidade do esquema imagético de contêiner é reinterpretada metaforicamente, na sentença (1): a recessão econômica é percebida como um recipiente abstrato, que não preserva a geometria de um contêiner. A geometria é desfeita, em benefício dos outros elementos do esquema imagético: oposição dentro/fora, limites, completude da ação e afetação do Tema.

A oposição dentro/fora é essencial para a interpretação da metáfora. $\mathrm{O}$ cerne da informação em (1) é que a Espanha está de novo dentro da recessão. A recessão é a Meta para a qual a Espanha se deslocou. Na metáfora, a Meta é pensada como um estado de coisas, com limites bem definidos. Os limites físicos de um contêiner são reinterpretados em termos dos limites de um estado de coisas, no caso, a recessão econômica.

A completude da ação também está presente na metáfora. O mergulho na recessão implica que a Espanha (o Tema) está inteiramente inserida no estado de coisas que corresponde à Meta (a recessão).

Finalmente, a afetação do Tema é, também, um elemento essencial da interpretação da metáfora. O mergulho da Espanha na recessão implica que este país está num estado lastimável, do ponto de vista econômico. O ambiente recessivo envolve e define o estado atual da economia espanhola. Estar em recessão afeta drasticamente o estado da Espanha. Pode-se concluir que os elementos do esquema imagético interferem diretamente na interpretação da metáfora. Na seção anterior, havíamos visto que os Elementos dos Frames associados aos sentidos literais dos verbos estudados também afetam a interpretação das metáforas.

Não obstante, esses dois fatores intervenientes (frames e esquema imagético) não esgotam a interpretação que damos às metáforas estudadas. É importante 
MOURA - Elementos nucleares de frame e a interpretação ...

considerar também como interagem os conceitos que entram no enunciado metafórico. Assim, cada combinação conceitual de argumentos e verbos de uma metáfora gera uma instância metafórica particular, que enriquece e complementa os padrões interpretativos oferecidos pelos frames e pelos esquemas imagéticos.

\section{METÁFORAS COMO INTERAÇÃO DE CONCEITOS}

A ligação de metáforas a frames e esquemas imagéticos possibilita a identificação de classes de metáforas, com características comuns. Pode-se identificar, por exemplo, um conjunto $C^{l}$ de metáforas ligadas ao esquema imagético de contêiner, um conjunto $C^{2}$ de metáforas ligadas ao frame COLOCAR, e assim por diante. Essa configuração em classes é um modo interessante e produtivo de analisar um corpus metafórico, mas ela não captura a particularidade de cada metáfora, que surge da combinação de dois conceitos específicos. Examine as duas sentenças abaixo:

(15) Com a carreira violentamente amputada, Simonal mergulhou na depressão. bravonline.abril.com.br/materia/idolo-linchado

(16) O diretor e cineasta Luiz Fernando Carvalho mergulhou no mundo dos ciganos da Rússia, Sérvia e Polônia, para construir sua nova série "A Aldeia”, que será transmitida pela Rede Globo em breve. fragmentosfractais.blogspot. com/.../luiz-fernando-carvalho-mergulho...

Nos dois casos, temos um mesmo verbo (mergulhar), em duas ocorrências metafóricas. Os Elementos de Frame e de esquema imagético de contêiner são relevantes para essas duas metáforas. O quadro 5, abaixo, apresenta os Elementos do Frame COLOCAR, relativos às metáforas (15) e (16), e o Quadro 6 lista os elementos semânticos derivados do esquema imagético de contêiner.

\section{Temas: Simonal: O diretor e cineata Luiz Fernando Carvalho \\ Metas: depressão: o mundo dos ciga- nos da Rússia, Sérvia e polônia}

Quadro 5 Elementos do Frame COLOCAR, relativos às sentenças (15) e (16)

$$
\begin{aligned}
& \text { Oposição dentro/fora: dentro da } \\
& \text { depressão; dentro do mundo dos } \\
& \text { ciganos } \\
& \text { Limites: A depressão e o mundo dos } \\
& \text { ciganos são situações circunstanciais. } \\
& \text { Completude da ação: mergulho }
\end{aligned}
$$

Quadro 6: Elementos semânticos derivados do esquema imagético de contêiner, relativos às sentenças (15) e (16) 
O paralelismo entre as metáforas em (15) e (16) é bastante grande, em função dos Elementos de Frame e do esquema imagético, que são equivalentes nos dois casos.

O meu ponto é que esses elementos comuns não esgotam a interpretação específica das duas metáforas. A interação do verbo mergulhar com os seus argumentos é também essencial. Considere, por exemplo, a questão dos limites, associado ao esquema imagético de contêiner. A depressão configura um estado emocional bem definido. Trata-se de um estado uniforme de tristeza e desânimo. É um estado que não implica mudanças e variação. Um estado depressivo só varia na intensidade, não na qualidade.

Já na metáfora em (16), o mergulho numa cultura estranha implica a inserção num estado de coisas (no caso, o mundo dos ciganos) que se caracteriza pela variação e pela multiplicidade. O mundo de uma cultura envolve diferentes hábitos, gestos, sensações e crenças, e alguém que mergulha numa cultura diferente deve vivenciar todos essas situações distintas e entrelaçadas. O mergulho, aqui, envolve a passagem por diferentes mudanças.

Por consequência, a afetação do Tema também é totalmente diferente nos dois casos. Entende-se que o cantor Simonal, ao mergulhar na depressão, chegou a um estado de imobilidade e tristeza, ficando imerso, paralisado, nesse ambiente sem variação. Já no caso do cineasta Luiz Fernando Carvalho, o mergulho no mundo dos ciganos tem um efeito completamente diverso. Ele deve ter ficado excitado com as experiências variadas e intensas, com a contínua mudança de ambientes e de situações de aprendizado. Portanto, a ideia que fazemos de mergulho muda, de acordo com o termo que se combina com o verbo.

A completude da ação também muda, nos dois casos. O mergulho na depressão é intenso, porque doloroso e integral. A pessoa se envolve profundamente no ambiente uniforme da depressão. O mergulho é uma espécie de naufrágio.

Já no caso do mergulho em uma cultura estranha, trata-se mais de um passeio por diferentes experiências, como se a pessoa tivesse colocado um tubo de oxigênio e mergulhado em águas profundas, ricas de uma vida vibrante e desconhecida.

Não é surpreendente que frames e esquemas imagéticos não deem conta da especificidade dessas interpretações metafóricas. Os frames e os esquemas são muito menos numerosos de que os conceitos que usamos. O conceito de cultura, por exemplo, evoca uma série de informações específicas, que devem ser combinadas com o conceito de mergulho, gerando a interpretação particular da metáfora da sentença (16), que, aliás, pode variar muito, de indivíduo para indivíduo.

Portanto, para a interpretação de metáforas, é preciso investigar a "transação entre contextos", segundo a fórmula proposta por Richards (1965), cujo texto original é de 1936. A combinação de mergulho e cultura resulta de uma relação entre dois contextos: o contexto que associamos a mergulho e o contexto que associamos a cultura. Essa relação entre contextos ganha sentido num enunciado específico, como a sentença (16). Como afirma Ricoeur (2005, p. 129), “a metáfora mantém dois pensamentos de coisas diferentes simultaneamente ativas no seio de uma palavra ou de uma expressão simples, cuja significação é resultante de sua interação". Em virtude dessa interação de conceitos e de contextos, o mergulho 
MOURA - Elementos nucleares de frame e a interpretação ...

não é o mesmo nas sentenças (15) e (16): mergulhar numa depressão é uma coisa inteiramente diversa de mergulhar numa cultura.

\section{CONCLUSÃo}

A conclusão principal deste artigo é que a interpretação de metáforas depende de muitos fatores distintos e interdependentes: os frames, os esquemas imagéticos e os conceitos que são utilizados no enunciado metafórico. Os frames e os esquemas imagéticos fornecem os padrões mais amplos de interpretação. Servem como um sistema de coordenadas para a tradução das ocorrências metafóricas. Mas esses padrões, exatamente por serem generalizadores, são em número limitado, e não podem dar conta de todas as distinções conceituais relevantes para a interpretação de uma metáfora.

Além disso, os conceitos, num enunciado metafórico, são extremamente sensíveis aos contextos. Nos verbos que foram analisados, o tipo de informação associada à Meta vai afetar diretamente como entendemos o mergulho, a imersão e o afogamento metafóricos. Essa oposição entre o mais geral (o frame) e o mais específico (o conceito associado a um item lexical) se reflete na própria estrutura do Projeto FrameNet. O site do projeto informa que 1159 frames já foram analisados e registrados, ao passo que o número de unidades lexicais registradas atingiu o número de 12571 itens, como se pode constatar no link https://framenet.icsi. berkeley.edu/fndrupal/current_status (consulta realizada em 23 de maio de 2012).

A relação é de mais de 10 unidades lexicais por frame. Isso quer dizer que a quantidade de informação conceitual associada aos itens lexicais é pelo menos dez vezes superior à quantidade de informação associada aos frames. A interpretação de uma metáfora recorre a essas duas fontes de informação: uma de natureza mais geral (o frame) e outra de natureza mais específica (o conceito).

É preciso ressaltar, também, que um conceito lexical depende muito do contexto no qual ele aparece. Por exemplo, na metáfora $O$ diretor e cineasta Luiz Fernando Carvalho mergulhou no mundo dos ciganos da Rússia, Sérvia e Polonia, o conceito de cultura evocado é muito particular e dependente do contexto. Não se trata de um mundo qualquer, mas de uma cultura diferente e com marcas fortes, como é a dos ciganos do leste europeu.

A tradição dos estudos da metáfora ora tem focado o fator mais contextual na interpretação, ora o fator mais generalizador. A teoria contextual de Richards (1965) é um exemplo da primeira abordagem, que foca o particular e o específico. Para Richards (1965), a metáfora é uma transação entre contextos. Não há, assim, o recurso a um sistema interpretativo mais amplo, que "traduza", de modo efetivo, as metáforas. De fato, a recusa à aceitação de um padrão de interpretação prévio implica que se dê um papel preponderante ao contexto. Quanto menos padrão interpretativo, mais contexto. Na teoria de Richards (1965), o particular se sobrepõe ao geral. 
Num outro extremo das opções teóricas, a teoria da metáfora conceptual (LAKOFF \& JOHNSON, 1980; LAKOFF, 1987) enfatiza os padrões interpretativos das metáforas. O geral se sobrepõe ao específico. A metáfora conceptual equivale a um sistema de tradução, que "traduz" metáforas particulares. Em função disso, o contexto se torna bastante secundário, na perspectiva da teoria da metáfora conceptual (cf. LEEZENBERG, 2001).

A análise dos verbos estudados neste artigo me leva a concluir que a interpretação de metáforas utiliza qualquer informação disponível nas estruturas conceituais e linguísticas, que estejam associadas ao enunciado metafórico. Informações sobre os frames, esquemas cognitivos e conceitos são buscadas onde elas estiverem disponíveis. A fonte da informação pode ser muito variada: ela pode provir de um Elemento Nuclear de Frame, que em tese seria mais acessível ao falante, ou a informação pode se originar de uma fonte muito particular, como as informações de que o falante dispõe sobre o mundo dos ciganos do Leste europeu. Um desenvolvimento desta pesquisa consistirá na investigação do papel de cada um desses fatores (frames, esquemas cognitivos e conceitos) em um corpus maior do que o examinado neste artigo.

\section{REFERÊNCIAS BIBLIOGRÁFICAS}

ALTERnBERG, B.; GRANGER, S. (2002). (Eds.). Lexis in Contrast: Corpus-based Approaches. Amsterdam: John Benjamins.

JOHNSON, M. (1987). The body in the mind: The bodily basis of meaning, imagination, and reason. Chicago: University of Chicago Press, 233 p.

LAKOFF, G. (1987). Women, fire, and dangerous things: What categories reveal about the mind. Chicago: University of Chicago, $614 \mathrm{p}$.

LAKOFF, G.; JOHNSON, M. (2002). Metaphors we live by. Chicago: Chicago University Press, 1980. Edição brasileira: Metáforas da vida cotidiana. Tradução de M. S. Zanotto e V. Maluf. São Paulo: EDUC.

LANGACKER, R. (2002). Concept, image, and symbol. The cognitive basis of grammar. $2^{\text {nd }}$ edition. New York: Mouton de Gruyter, 395 p.

LEVINSON, S. (2003). Space in language and cognition. Cambridge:Cambridge University Press, $388 \mathrm{p}$.

LEEZENBERG, M. (2001). Contexts of Metaphor. Amsterdam: Elsevier, 321 p.

LÖNNEKER-RODMAN, B. (2007). Multilinguality and FrameNet. Technical Report. TR-07-001. Berkeley: ICSI.

MOURA, H. (2006). The conceptual and the linguistic factors in the use of metaphors. DELTA 22, n. especial, p. 81-94.

. (2007). Relações paradigmáticas e sintagmáticas na interpretação de metáforas. Linguagem em (Dis)curso 7-3, p. 417-452. 
MOURA - Elementos nucleares de frame e a interpretação ...

MOURA, H. M. M.; DAMÁZIO, P. (2011). A preposição em no espaço: um jogo de linguagem e cognição. In: Cambrussi, Morgana; Aragão Neto, Magdiel.. (Org.). Léxico e gramática. 1 ed. Curitiba: CRV, v. 1, p. 89-102.

MOURA, H. \& ZANOTTO, M. (2009). Investigando teórica e empiricamente a indeterminação da metáfora. Gragoatá, v. 26.

PEÑA, S. A. (2001). Cognitive approach to the role of body parts in the conceptualization of emotion metaphors. EPOS, vol. XVII, p. 245-260.

PIAGET, Jean \& INHELDER, B. (1967). The child's conception of space. New York: Norton, 1967. Tradução de Langdon, F. \& Lunzer, J.

PINKER, S. (2008). Do que é feito o pensamento. São Paulo: Companhia das Letras. 561 p.

RICHARDS, I. A. (1965). The philosophy of Rhetoric. Oxford: Oxford University Press, 138 p.

RICOEUR, Paul. (2005). A metáfora viva. São Paulo: Edições Loyola. 500p.

SALOMÃO, M. (2009). FrameNet Brasil: um trabalho em progresso. Calidoscópio,. Vol. 7, n. 3, p. 171-182.

TALMY, Leonard. (2003). Force Dynamics in Language and Cognition. In: Toward a Cognitive Semantics (vol I). Cambridge: MIT Press, 564 p.

VEALE, T. (2003). Systematicity and the Lexicon in Creative Metaphor. Proceedings of the ACL 2003 Workshop on the Lexicon and Figurative Language, p. 27-34. 